\title{
NEW CHALLENGES FOR THE TEACHING OF ARCHITECTURE
}

\author{
M.I. Alba Dorado \\ University of Málaga (SPAIN) \\ maribelalba@uma.es
}

The implementation of the European Higher Education Area (EHEA) opens us to a new scenario marked by a training model increasingly complex and extensive in time that differs considerably from that which has been done so far and that makes it necessary to think again University.

In this context, it is necessary to review the teaching model of the current Schools of Architecture: defining new strategies and reflection mechanisms according to the expectations of the degree and the postgraduate in our country and reconsidering the ways of teaching and learning, taking into account not only the what you want to teach, but also to how you are going to teach in order to move from the traditional model of transmission of knowledge from teacher to student, to a model based on the development of competences in the student, in which knowledge stops be stable and scarce to demand its expansion and update constantly throughout life and where the educational institution loses its exclusivity when transmitting knowledge and information. All this makes it necessary for the student to reach the capacity to acquire all those knowledge, skills and attitudes that will require throughout his life in his academic or professional training becoming the true protagonist of his own training.

For this, it is necessary to think of a teaching of architecture that defines more flexible learning pathways that support ongoing training. A teaching oriented more to show an attitude towards the project, to encourage, stimulate and involve students in their own learning process helping them to develop their capacity to learn to learn. In short, a teaching is demanded in which the training on information predominates with the aim of creating learning situations that facilitate a subsequent continuous training and that allow a more critical and deep intellectual development that enables to generate knowledge.

It requires a teaching that contemplates the complexity of the architectural fact and that conceives the teaching of Projects not as the transmission of a pre-established teaching or of a closed and complete architectural culture that tries to exhaust all the ways of knowledge, showing a strict method and infallible; rather, it requires an active and plural teaching, based on continuous research, participant in an open, flexible and dynamic disciplinary discourse. A teaching that shows a research attitude as a method both for the effective transmission of knowledge and for the development of skills that allow the student to generate new knowledge.

It is also necessary, from the teaching of Projects, to ensure the coordination of the subject of Projects with the rest of the subjects of the course with the aim of offering a global and unitary formation, not split by subjects or specialties. Likewise, from the 
teaching point of view, continuous training should be encouraged in all its areas, leading the student to become actively involved in his own training, incorporating experiences acquired both inside and outside the classroom into his learning process. And, the architecture, still learned, is always to be known, and this learning does not stop at the level of classes, but continues beyond time and space beyond the scope of the classroom and extending to all cultures architectural in general. 